\title{
Biomedical cellular product for wound healing
}

\author{
Alexander P Lykov*, Natalia A Bondarenko, Olga V Poveshchenko, Tatjana V Miller, Alexander F Poveshchenko, Maria A Surovtseva, Na- \\ talia P Bgatova, and Vladimir I Konenkov
}

Scientific Institute of Clinical and Experimental Lymphology, Novosibirsk, Russian Federation

\begin{abstract}
Bone marrow mesenchymal stem cells MSCs) secrete paracrine factors that may exert healing effect on the wounded tissues. This study was done to determinate the effect of MSCs or MSC-Conditioned Media MSC-CM) on the wound healing in intact mice, and under hyperglycemic condition. We established a burned wound healing mice diabetes mellitus DM) model and cultured primary bone marrow MCSs. A MSCs suspension or MSC-CM was injected into wound bed. Phenotype of MSCs, multiple differentiating capacities, and wound closure was determined. Secretion of cytokines or growth factors into culture media was determined by ELISA. MSCs and MSC-CM caused a rapid wound closure. MSCs secreted into the media a wide range of paracrine factors. These data demonstrate that MSCs promote wound healing in mice with or without STZ-induce diabetes mellitus through secretion of paracrine factors.
\end{abstract}

Abbreviations: B6: C57Bl6 mice; DM: Diabetes Mellitus; DFU: Diabetic Foot Ulcer; GM-CSF: Granulocyte/Macrophage-Colony stimulating factor; IL-1 $\beta$ : Interleukin 1 beta; IL-2: Interleukin 2; IL-4: Interleukin 4; IL-6: Interleukin 6; IL-10: Interleukin 10; IFNү: Interferon gamma; MSCs: Mesenchymal Stem Cells; MSC-CM: Mesenchymal Stem Cells-Conditioned Media; NO: Nitrite Oxide; TNFa: Tumor Necrosis Factor alpha; VEGF: Vascular endothelial growth factor

\section{Introduction}

Diabetic foot ulcers DFUs) are one of the major complications of diabetes mellitus worldwide [1]. Approximately $25 \%$ of these patients will have progressive disease that eventually leads to amputation [2-4]. Wound healing is a coordinated process comprising an inflammatory reaction, angiogenesis and formation of extracellular matrix accompanied by scar tissue remodeling. Cellular participants as well as multiple growth factors and cytokines released by the cells at the wound site regulate these processes and finally result in wound closure. Deregulated healing processes may delay repair and may eventually lead to chronic wounds, such as those observed in diabetes mellitus [57]. Mesenchymal stem cells MSCs) therapy has emerged as a novel and promising candidate approach for the treatment of DFUs, probably by be as progenitors of all connective tissue cells, decrease apoptosis, cell replacement and modulation on inflammation and immune response. MSCs have been shown to mobilize and home ischemic and wounded tissues where they secrete chemokines and growth factors to promote angiogenesis and extracellular matrix remodeling. Recently, MSCs transplantation has demonstrated significant wound healing in patients with DFUs [8-20]. In the present study, we established a delayed wound healing model in diabetic mice and evaluated the impact of MSCs engraftment, and injection of MSC-Conditioned Media on delayed wound healing.

\section{Materials and methods}

\section{General procedures}

All experimental protocols were approved by the Animal Care and Use Committee of the Institute of Clinical and Experimental
Lymphology, Novosibirsk, Russia, in accordance with guidelines of the National Institutes of Health Guide for the Care and Use of Laboratory Animals. The protocol of anesthesia, burn induction, post-burn care and sacrifice were identical for all animals. The animals were sacrificed under deep ether general anesthesia. Animal were housed under a 12hour light/dark cycle with free access to food and water. A total of 48 male C57Bl6 B6) mice weighing 20-25 g, were housed 5 per cage in room maintained at $22 \pm 0.5^{\circ} \mathrm{C}$ and relative humidity of $65-70 \%$. The animals were allowed to adapt to the laboratory for at least 2-hour before testing and were only used once. Experiments were performed during the light phase of the cycle 10:00-17:00).

\section{Isolation of bone marrow derived mesenchymal stem cells and culture conditions}

Whole bone marrow was isolated from both the femurs of intact B6 mice. Bone marrow was aspirated with a syringe with a 26-gauge needle, containing $1 \mathrm{~mL}$ heparin, and disaggregated into a single-cell suspension. Mononuclear cells were separated by density-gradient centrifugation over Ficoll-Paque Sigma). The cells were seeded onto culture T-25 flask at $1 \times 10^{5}$ cells $/ \mathrm{cm}^{2}$ with $37^{\circ} \mathrm{C} / 5 \% \mathrm{CO}_{2}$ in culture medium containing Dulbecco's modified Eagle's medium DMEM; Hyclone) supplemented with $10 \%$ heat-inactivated fetal caw serum FCS, Hyclone), $80 \mu \mathrm{g} / \mathrm{mL}$ gentamycin Gibco). Three days later, nonadherent cells were removed by changing the medium. After 14 days in culture, adherent cells were passaged with $0.05 \%$ trypsin-EDTA Gibco). Mesenchymal stem cells-Conditioned Media MSC-CM) was prepared by plating $2 \times 10^{6}$ MSCs in $10 \mathrm{~mL}$ DMEM supplemented with

Correspondence to: Alexander P. Lykov, Scientific Institute of Clinical and Experimental Lymphology, Novosibirsk, Russian Federation; E-mail: aplykov2@mail.ru

Key words: into wound bed injection, mesenchymal stem cell, conditioned media, diabetes mellitus

Received: December 20, 2015; Accepted: January 14, 2016; Published: January 18,2016 
$10 \%$ FCS, $80 \mu \mathrm{g} / \mathrm{mL}$ on T-25 flask for 48 -hours. Following culture, the media was filtered through a $0.22 \mathrm{~mm}$ membrane.

\section{Characterization of MSCs}

MCSs of passage 3 incubated with monoclonal PE-conjugated antibodies for CD34 and CD73, with FITC-conjugated antibodies for CD90, and CD45, and with APC-conjugated antibodies for CD105 BD) in the dark for $30 \mathrm{~min}$ at $40 \mathrm{C}$. The cells were subsequently washed three times with phosphate buffer solution PBS), resuspended in $500 \mu \mathrm{LFACS}$ buffer $0.05 \% \mathrm{NaN}_{3}+5 \%$ FCS in PBS) and analyzed on FACSCanto II $\mathrm{BD})$ using FACSDiva BD). Adipocytes differentiation was induced in DMEM culture medium containing 1-methyl-3-isobutylxanthine, $10^{-9}$ $\mathrm{M}$ dexamethasone, $5 \mathrm{mM}$ insulin and $5 \mathrm{mM}$ indomethacin. Osteogenic differentiation was induced in DMEM culture medium containing $50 \mu \mathrm{g} / \mathrm{mL}$ ascorbic acid, $10 \mathrm{mM} \beta$-glycerophosphate and $10^{-9} \mathrm{M}$ dexamethasone. The medium was replaced every 2-3 days for 14 days. Matured adipocytes that formed lipid vacuoles were stained with oil red O Sigma) staining. Calcium formation of cells with a rounder shape was demonstrated by staining with alizarin red S Sigma), a marker for the osteocytes phenotype.

\section{Streptozotocin-induced diabetes mellitus}

Diabetes mellitus was induced in 24 B6 male mice. B6 mice were starved for at least 12-hour before a single intraperitoneal injection of streptozotocin STZ, Sigma) dissolved in sodium citrate buffer $0.1 \mathrm{mM}$, $\mathrm{PH} 4.4$ ) at a dose of $60 \mathrm{mg} / \mathrm{kg}$. At day 0 and during 28 days following after STZ injection, blood samples were obtained from the tail vein, and the blood glucose levels were measured by glucometer AccuCheck Advantage and AccuCheck Comfort Strips, Roche; Branchburg, NJ). STZ-treated B6 mice with blood glucose levels above $15 \mathrm{mM} / \mathrm{L}$ were considered diabetic and were used in this study.

\section{Wound creation and treatment}

The hair was clipped from the back of each animal with standard animal clippers. 24 B6 mice with STZ-diabetes and 24 B6 mice without STZ-diabetes were anesthetized and burns were induced on the thigh using $1 \times 2 \mathrm{~cm}$ piece of hot metal, producing a burn of up to $10 \%$ of the total body surface and extending to all layers of skin but not involving the muscular tissue. At day 0 after wounding, $1 \times 10^{6}$ MSCs in $200 \mu \mathrm{L}$ PBS MSCs wounds; $\mathrm{n}=8$ ), $200 \mu \mathrm{L}$ MSC-CM MSC-CM wounds; $\mathrm{n}=8$ ), and $200 \mu \mathrm{L}$ PBS PBS wounds; $\mathrm{n}=8$ ) were inoculated into the wound bed. The wounds were observed daily. Estimates of wound area were calculated from the product of two mutually perpendicular perimeters. Wound area was measured using a caliper. Wound healing was quantitatively measured and calculated by the remaining wound area.

\section{Histopathological examination}

Skin wound sites on day 30 after injury, excised from the mice, were fixed in $4 \%$ formalin for 4 -hour at room temperature prior to embedding in paraffin. $5 \mu \mathrm{m}$ thickness paraffin sections were dewaxed, rehydrated, washed and stained with hematoxylin-eosin H\&E). At least three skin sections per mouse were analyzed.

\section{ELISA for MSCs culture medium}

Supernatants were collected from MSCs. The concentration of IL-1 $\beta$, IL-2, IL-4, IL-6, IL-10, TNF- $\alpha$, IFN- $\gamma$, VEGF, and GM-CSF were measured using sandwich enzyme-linked immunosorbent assay ELISA) kits eBioscience, Austria), according to the manufacturer's instructions.

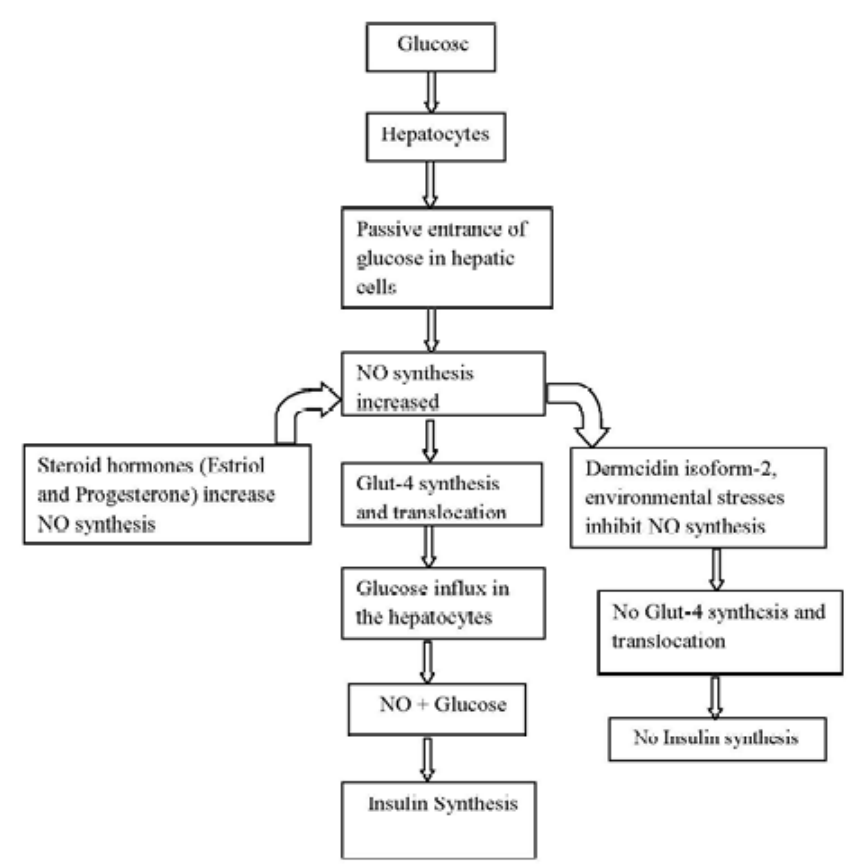

Figure 1. Diagrammatical representation of the role of glucose, nitric oxide (NO), dermcidin isoform-2 and Glut- 4 in the synthesis of insulin in hepatocytes.

\section{Nitrite production}

Nitrite was measured as an indicator of nitrite oxide NO) production in supernatants from MSCs. NO inhibition assay was conducted using Griess reagent kit for nitrite determination Molecular Probes). The amount of NO was calculated using a sodium nitrite standard curve.

\section{Statistical analysis}

Data were analyzed by the Statistica 6.0 for Windows. All data obtained are presented as the mean \pm SEM standard error of the mean). The differences between mean values were tested for significance using the nonparametric Mann-Whitney $U$ test.

\section{Results}

\section{MSCs culture and characterization}

MSCs were successfully isolated from non-diabetic Bl6 mice bone marrow. Cells were cultured to passage three and used for cellular therapy. The cells exhibited heterogeneous morphology on day 3 and produced an adherent layer on day 14. MSCs on tissue culture plastic demonstrated spindle-shaped morphology on becoming confluent Figure 1a). To identify MSCs characteristics, phenotypes and multiple differentiating capacities of cultured BM-derived adherent cells at passage three were analyzed, respectively.

Flow cytometry confirmed the characteristic expressions of mesenchymal stem cells related to surface markers. The mouse MSCs were $94.5 \%$ positive for CD73, 95\% positive for CD90, 94.6\% positive for CD105, 98.5\% negative for CD34, and $97.8 \%$ negative for CD45 Figure 1d).

The capacity of the MSCs to differentiate into osteocytes and adipocytes was demonstrated in vitro. The cells that were maintained in adipocytes differentiation condition for 2 weeks exhibited lipid 
vacuoles in the colonies as indicated by oil red $\mathrm{O}$ stain Figure $1 \mathrm{~b}$ ). MSCs that were conditioned in osteogenic differentiation media for 2 weeks exhibited calcium deposition as indicated by alizarin red $\mathrm{S}$ stain Figure 1c).

\section{Growth Factors and Cytokines in MSC-Conditioned Media}

Levels of growth factors and cytokines were measured in MSC-CM using ELISA. Different levels of the IL- $1 \beta$, TNF- $\alpha$, IL-2, IL-4, IL-6, IL10 , INF- $\gamma$, GM-CSF, VEGF and NO were found in MSC-CM Table 1).

\section{Induction of diabetes mellitus in the animal model}

The animal remained hyperglycemic post-STZ infusion over the study time period higher than $15 \mathrm{mM} / \mathrm{L}$ Table 2). There was no mortality post-STZ treatment. The blood glucose levels were checked by glucometer. These results suggested that intraperitoneal administration of STZ induce Diabetes Mellitus in B6 mice

\section{MSCs Grafts and MSC-CM Injection Promote Healing of Wounds}

The burned wounds were prepared on the dorsum of intact B6 male mice and in STZ-induced Diabetes Mellitus B6 male mice. Control animals received identical burned wounds without MSCs or MSC$\mathrm{CM}$ engraftment to measure baseline healing. Engraftment with MSCs and injection MSC-CM helped discriminate between the effect of local delivery of cells and the subsequent systemic response. The response on the grafted animals revealed direct, cell-mediated effect of engraftment, whereas the response on the injection MSC-CM revealed the extent of the indirect systemic effect of MSC-CM injection on promoting wound healing Table 3).

Accelerated healing persisted in the MSCs and MSC-CM wounds through days 21 and 24 in intact mice, and through days 7 and 21 in STZ-induced Diabetes Mellitus mice. We found that the MSCs or MSC-CM wounds exhibited significantly improved closure in normal healing and in diabetic mice $\mathrm{p}<0.05$ ) at time point, days, $7,14,21$, and 24 Table 2).

Next, we examined the impact of MSCs engraftment or MSC-CM injection on reepithelialization. As shown in Figure 2, the epithelial thicker showed no differences among these groups on day 30 . However, the epithelial was thicker in all experimental groups compare normal skin.

These findings suggested that MSCs or MSC-CM may participate in and promote the formation of derma by topical wound bed transplantation.

We also evaluated the impact of MSCs or MSC-CM on hair follicle, sebaceous gland, and blood vessels formation in wound Table 4).

The MSCs or MSC-CM promotes significantly of hair follicles, sebaceous glands, and blood vessels formation in wound induced in diabetic mice.

\section{Discussion}

Wound healing is a complex process, which includes: coagulation, inflammation, migration/proliferation, and remodeling [6,21]. Infection, hypoxia, high levels of proinflammatory cytokines, which leads to induction of chronic inflammation in wound, are factors that can impair wound healing in DFUs $[1,4,7]$. For good wound healing in DFUs should be combination of reduction inflammation, forming of granulation tissue, high epithelial cell proliferation and neoangiogenesis. MSCs are important cells in orchestrating wound healing process inflammatory, proliferation, and remodeling) $[2,12]$. Patients with DFUs characterized by poor wound healing, and are highly resistant to standard therapy. Therefore, there has been increased interest in stem cell therapy, include MSCs [10,12,13,15-19,22].

MSCs are multipotent stem cells that can differentiate into variety of cell types, including connective tissue. Moreover, MSCs modulate local environment in damage tissues, activate endogenous progenitor cells, and secrete various factors [23-28]. It is very good known that intravenous administration of MSCs lead to a cell loss and to decrease efficacy of cellular therapy [18-19,29]. To solve these problem stem cells must be injected in pathological area.

In the present study, engraftment of MSCs or injection of MSC$\mathrm{CM}$ into wound bed demonstrated a good recovery of delayed skin in normal mice, and in mice with STZ-induced Diabetes Mellitus. Mane findings of this study are the following: 1) topical engraftment of MSCs or topical injection of MSC-CM promoted reepithelialization; 2) engraftment of MSCs or injection of MSC-CM significantly enhanced hair follicle, sebaceous gland, and blood vessels formation in wound; 3 ) MSCs promoted wound healing through paracrine factors in normal mice, and in diabetic mice.

Topical engraftment of MSCs or topical injection of MSC-CM to sites of injury modulated inflammation and tissue remodeling. There are many studies indicated that MSCs possible differentiate into keratinocytes, epithelial cells, and endothelial cells in skin $[6,12,14,19]$. Multiple differentiating capacities and production of wide range of cytokines, and growth factors have both implicated as mechanisms by which MSCs promote tissue repair skin $[6,12,14,19]$. Multiple differentiations are necessary to regeneration of damage tissue, but paracrine factors productions are important in reduction of inflammation, promotes neoangiogenesis skin $[6,12,14,19]$.

Reepithelialization is essential steps of wound healing, which protect from infection in wound. On day 7 in intact mice, wound reepithelialization in MSCs wounds, and MSC-CM wounds was significantly higher $60 \%$ and $62 \%$, compare with PBS wounds; $\mathrm{p}<0.05$ ). On day 24 in intact mice, these parameters significantly increased, and compose $98 \%$ and $90 \%$, respectively $\mathrm{p}<0.05$ ).

On day 7 in STZ-induced Diabetes Mellitus mice, wound cover by epithelium in MSCs wounds, and MSC-CM wounds was achieved $70 \%$ and $60 \%$, respectively $\mathrm{p}<0.05$ ), whereas in PBS wounds we observed the increasing of wound area. On day 24 in diabetic mice, reepithelialization increased to $98 \%$ and $90 \%$, respectively $\mathrm{p}<0.05$ ), compare with PBS wounds.

Moreover, histological finding indicates that MSCs, and MSC-CM significantly promote restoration of skin in wound area, compare with PBS wounds. Such, we observed significant increasing of hair follicle $762 \%$ and $972 \%$, respectively for MSCs wounds and MSC-CM wounds), sebaceous gland $187 \%$ and $312 \%$, respectively for MSCs wounds and MSC-CM wounds), blood vessels $416 \%$ and $458 \%$, respectively for MSCs wounds and MSC-CM wounds), compare with PBS wounds in diabetic mice on day 30 .

In our study, we demonstrated that MSCs wounds and MSC-CM wounds had enhanced blood vessels formation, suggesting that MSCs promote neoangiogenesis. Indeed, we also found increased levels production by MSCs into culture media of VEGF, IL- $1 \beta$, TNF- $\alpha$, IFN- $\gamma$, and NO. Cytokines and growth factors are also known to play a role in regulating the proliferation, differentiation and migration of 
cells during wound healing, while VEGF may stimulate angiogenesis to promote healing [23-28]. VEGF are essential to neoangiogenesis, which stimulate endothelial progenitor cells migration and proliferation in damage tissue [1,4,22,24-25,28,30]. It is well known, that chronic inflammation in DFUs in part are the result of the lack of neoangiogenesis $[7,23,31]$. Our results demonstrated that MSCs able to produce enough levels of VEGF in culture media, and when it's engraftment into wound bed, they also able to secreted VEGF. Moreover, injection MSC-Conditioned Media alone into wounds bed confirms these.

In conclusion, our comparative study, following burned wound creation in intact mice and mice with STZ-induced Diabetes Mellitus suggest that a therapeutic benefit is associated with the into wound bed injection of biomedical cellular product after burned injury to the skin. Our results demonstrate that the into wound bed injection of MSCConditioned Media are as effective as MSCs in promoting wound healing. Both biomedical cellular products are ethically acceptable for clinical application in the treatment of DFUs.

\section{Competing interests}

The authors declare that they have no competing interests.

\section{Authors' contributions}

AP Lykov carried out the STZ-induced DM, carried out the blood glucose level, carried out the burn wound creation and treatment, carried out the immunoassay, performed statistical analysis, wrote the paper. NA Bondarenko carried out isolation, cultivation, characterization of BM-MSCs, carried out MSC-CM. OV Poveshchenko conceived and designed experiments. TV Miller carried out the STZ-induced DM. AF Poveshchenko conceived and designed experiments. MA Surovtseva carried out isolation and cultivation of BM-MSCs. NP Bgatova performed histopathological examination. VI Konenkov participated in the design of the study and coordination and helped to draft the manuscript. All authors read and approved the manuscript.

\section{Acknowledgements}

We wish to thanks Irina Kim for help with phenotype characterization of BM-MSCs.

\section{References}

1. Zhang J, Guan M, Xie C, Luo X, Zhang Q, et al. (2014) Increased growth factors play a role in wound healing promoted by noninvasive oxygen-ozone therapy in diabetic patients with foot ulcers. Oxid Med Cell Longev 2014: 273475. [Crossref]

2. Sena CM, Bento CF, Pereira P, Seiça R (2010) Diabetes mellitus: new challenges and innovative therapies. EPMA $J$ 1: 138-163. [Crossref]

3. Tuttolomondo A, Maida C, Pinto A (2015) Diabetic foot syndrome: Immuneinflammatory features as possible cardiovascular markers in diabetes. World J Orthop 6: 62-67. [Crossref]

4. Tecilazich F, Dinh T, Pradhan-Nabzdyk L, Leal E, Tellechea A, et al. (2013) Role of endothelial progenitor cells and inflammatory cytokines in healing of diabetic foot ulcers. PLoS One 8: e83314. [Crossref]

5. Tang Y, Zhang MJ, Hellmann J, Kosuri M, Bhatnagar A, et al. (2013) Proresolution therapy for the treatment of delayed healing of diabetic wounds. Diabetes 62: 618-627. [Crossref]

6. Nuschke A (2014) Activity of mesenchymal stem cells in therapies for chronic skin wound healing. Organogenesis 10: 29-37. [Crossref]

7. Demidova-Rice TN, Hamblin MR, Herman IM (2012) Acute and Impaired Wound Healing: Pathophysiology and Current Methods for Drug Delivery, Part 2: Role of Growth Factors in Normal and Pathological Wound Healing: Therapeutic Potential and Methods of Delivery. Adv Skin Wound Care 25: 349-370. [Crossref]
8. Cao Z, Zhang G, Wang F, Liu H, Liu L, et al. (2013) Protective effects of mesenchymal stem cells with CXCR4 up-regulation in a rat renal transplantation model. PLoS One 8: e82949. [Crossref]

9. Gutierrez-Fernandez M, Rodriguez-Frutos B, Ramos-Cejudo J, Otero-Ortega L, Fuentes B, et al. (2013) Effect of intravenous administration of allogenic bone marrowand adipose tissue-derived mesenchymal stem cells on functional recovery and brain repair markers in experimental ischemic stroke. Stem Cell Res Ther 4: 11-26. [Crossref]

10. Si Y, Zhao Y, Hao H, Liu J, Guo Y, et al. (2012) Infusion of mesenchymal stem cells ameliorates hyperglycemia in type 2 diabetic rats: identification of a novel role in improving insulin sensitivity. Diabetes 61: 1616-1625. [Crossref]

11. Jiang Y, Zhang Y, Zhang L, Wang M, Zhang X, et al. (2014) Therapeutic effect of bone marrow mesenchymal stem cells on laser-induced retinal injury in mice. Int J Mol Sci 15: 9372-9385. [Crossref]

12. Pileggi A (2012) Mesenchymal stem cells for the treatment of diabetes. Diabetes61: 1355-1356. [Crossref]

13. Yeung TY, Seeberger KL, Kin T, Adesida A, Jomha N, et al. (2012) Human mesenchymal stem cells protect human islets from pro-inflammatory cytokines. PLoS One 7: e38189. [Crossref]

14. Ricciardi M, Malpeli G, Bifari F, Bassi G, Pacelli L, et al. (2012) Comparison of epithelial differentiation and immune regulatory properties of mesenchymal stromal cells derived from human lung and bone marrow. PLoS One 7: e35639. [Crossref]

15. Wan J, Xia L, Liang W, Liu Y, Cai Q (2013) Transplantation of bone marrow-derived mesenchymal stem cells promotes delayed wound healing in diabetic rats. $J$ Diabetes Res 2013: 647107. [Crossref]

16. Allen RJ Jr, Soares MA, Haberman ID, Szpalski C, Schachar J, et al. (2014) Combination therapy accelerates diabetic wound closure. PLoS One 9: e92667. [Crossref]

17. Bernardi S, Severini GM, Zauli G, Secchiero P (2012) Cell-based therapies for diabetic complications. Exp Diabetes Res2012: 872504. [Crossref]

18. O’Loughlin A, Kulkarni M, Creane M, Vaughan E, Mooney E, et al. (2013) Topical Administration of Allogeneic Mesenchymal Stromal Cells Seeded in a Collagen Scaffold Augments Wound Healing and Increases Angiogenesis in the Diabetic Rabbit Ulcer. Diabetes 62: 2588-2594. [Crossref]

19. Wan J, Cai Q, Liu Y (2013) Effect of different transplantations with bone-marrow derived mesenchymal stem cells on diabetic foot ulcers in rats. Zhong Nan Da Xue Xue Bao Yi Xue Ban 38: 347-355. [Crossref]

20. Yeum CE, Park EY, Lee SB, Chun HJ, Chae GT (2013) Quantification of MSCs involved in wound healing: use of SIS to transfer MSCs to wound site and quantification of MSCs involved in skin wound healing. J Tissue Eng Regen Med 7: 279-291. [Crossref]

21. Pastar I, Stojadinovic O, Yin NC, Ramirez H, Nusbaum AG, et al. (2014) Epithelialization in Wound Healing: A Comprehensive Review. Adv Wound Care (New Rochelle) 3: 445-464. [Crossref]

22. Mishra PJ, Mishra PJ, Banerjee D (2012) Cell-free derivatives from mesenchymal stem cells are effective in wound therapy. World J Stem Cells 4: 35-43. [Crossref]

23. Shin L, Peterson DA (2013) Human Mesenchymal Stem Cell Grafts Enhance Normal and Impaired Wound Healing by Recruiting Existing Endogenous Tissue Stem/ Progenitor Cells. Stem Cells Transl Med 2: 33-42. [Crossref]

24. Chen L, Tredget EE, Wu PY, Wu Y (2008) Paracrine factors of mesenchymal stem cells recruit macrophages and endothelial lineage cells and enhance wound healing. PLoS One 3: e1886. [Crossref]

25. Hoch AI, Binder BY, Genetos DC, Leach JK (2012) Differentiation-dependent secretion of proangiogenic factors by mesenchymal stem cells. PLoS One 7: e35579. [Crossref]

26. Melief SM, Geutskens SB, Fibbe WE, Roelofs H (2013) Multipotent stromal cells skew monocytes towards an anti-inflammatory interleukin-10-producing phenotype by production of interleukin-6. Haematologica 98: 888-895. [Crossref]

27. Pradhan Nabzdyk L, Kuchibhotla S, Guthrie P, Chun M, Auster ME, et al. (2013) Expression of neuropeptides and cytokines in a rabbit model of diabetic neuroischemic wound healing. J Vasc Surg 58: 766-775. [Crossref]

28. Boomsma RA, Geenen DL (2012) Mesenchymal stem cells secrete multiple cytokine that promote angiogenesis and have contrasting effects on chemotaxis and apoptosis PLoS One 7: e35685. [Crossref]

29. Beyazyıldız E, Pınarlı FA, Beyazyıldız O, Hekimoğlu ER, Acar U, et al. (2014) Efficacy of topical mesenchymal stem cell therapy in the treatment of experimental dry eye syndrome model. Stem Cells Int 2014: 250230. [Crossref] 
30. Baraniak PR, McDevitt TC (2010) Stem cell paracrine actions and tissue regeneration. Regen Med 5: 121-143. [Crossref]
31. Rennert RC, Sorkin M, Januszyk M, Duschar D, Kosaraju R, et al. (2014) Diabetes impairs the angiogenic potential of adipose-derived stem cells by selectively depleting cellular subpopulations. Stem Cell Res Ther 5: 79-94. [Crossref]

Copyright: (C2015 Lykov AP. This is an open-access article distributed under the terms of the Creative Commons Attribution License, which permits unrestricted use, distribution, and reproduction in any medium, provided the original author and source are credited. 